16 a 18 de autubro de 2019 - Campinas | Brasil

\title{
ENVELHECIMENTO DA SUBSTÂNCIA CINZENTA EM PACIENTES COM EPILEPSIA
}

\author{
José Carlos de Almeida Junior, Eufrásio de Andrade Lima Neto, Aluísio Pinheiro, Fernando Cendes, Clarissa \\ Lin Yasuda
}

\section{Resumo}

A epilepsia é uma condição neurológica mundial com uma carga global de 1\%, equivalente ao câncer de mama em mulheres e câncer de pulmão em homens. Independentemente dos avanços nas drogas antiepilépticas, aproximadamente $30 \%$ dos pacientes permanecem farmacorresistentes. Objetivo deste trabalho é estudar a diferença entre o envelhecimento da massa cinzenta de pacientes com epilepsia em relação a pessoas saudáveis.

\section{Palavras-chave:}

Epilepsia, regressão, estatística.

\section{Introdução}

A melhor compreensão das alterações cerebrais ao longo do tempo permitirá o desenvolvimento de estratégias mais específicas para prevenir a atrofia cerebral generalizada desde as primeiras idades e possivelmente reforçar a necessidade de cirurgias precoces para pacientes com resistência farmacológica..

Objetivo: Comparar curvas de envelhecimento entre sujeitos sadios e diversos tipos de epilepsia.

Métodos:Utilizando técnicas de regressão para comparar os pacientes e controles. Ao todo foram 698 observações na amostra, 291 controle e 398 pacientes. Todos os modelos foram ajustados com o auxílio do software R.

Foram estudadas 74 regiões do cérebro, para cada uma dessas 74 regiões foram ajustados modelos de regressão linear para o grupo controle e para o grupo pacientes. Para todos os modelos, foi necessário fazer análise dos resíduos para verificar se as suposições de normalidade, variância constante e de independência foram satisfeitas.

\section{Resultados e Discussão}

Um resumo dos modelos ajustados, encontra-se na tabela abaixo.

Tabela 1. Modelos de regressão para 2 regiões.

\begin{tabular}{llccc} 
Grupo & Região & $\beta_{0}$ & $\beta_{1}$ & $\begin{array}{c}\text { Suposições } \\
\text { dos Resíduos }\end{array}$ \\
\hline Controle & $\begin{array}{c}\text { Lbankssts } \\
\text { thickavg }\end{array}$ & 2.706 & -0.006 & OK \\
\hline Paciente & $\begin{array}{l}\text { Lbankssts } \\
\text { thickavg }\end{array}$ & 2.665 & -0.007 & OK \\
\hline Controle & $\begin{array}{l}\text { L_caudala } \\
\text { nter }\end{array}$ & 2.949 & 0.005 & OK \\
\hline Paciente & $\begin{array}{l}\text { L_caudala } \\
\text { nter }\end{array}$ & 2.454 & -0.0037 & OK \\
\hline
\end{tabular}

Ajustados os modelos, o próximo passo foi comparar as retas ajustadas no grupo controle com as do grupo pacientes e em cada uma das regiões. A tabela 2, mostra essa comparação para a região bankssts_thickavg".

Observando a tabela é possível notar que, um paciente com 20 anos, possui a região do cérebro equivalente a uma pessoa saudável com 27.9 anos. Um paciente com 25 possui a região do cérebro equivalente a um saudável com 33.3. Ou seja, a região cérebro do paciente está mais envelhecida do que a região cérebro de um não doente

Tabela 1. Comparação idade paciente e controle.

\begin{tabular}{ccc} 
& Idade Paciente & Idade Controle \\
\hline 1 & 20 & 27.9 \\
\hline 2 & 25 & 33.3 \\
\hline 3 & 30 \\
\hline 4 & 35.8 \\
\hline 5 & 44.3 \\
\hline 40 & 49.7 \\
\hline
\end{tabular}

Figura 1. Observações e Retas de Regressão.

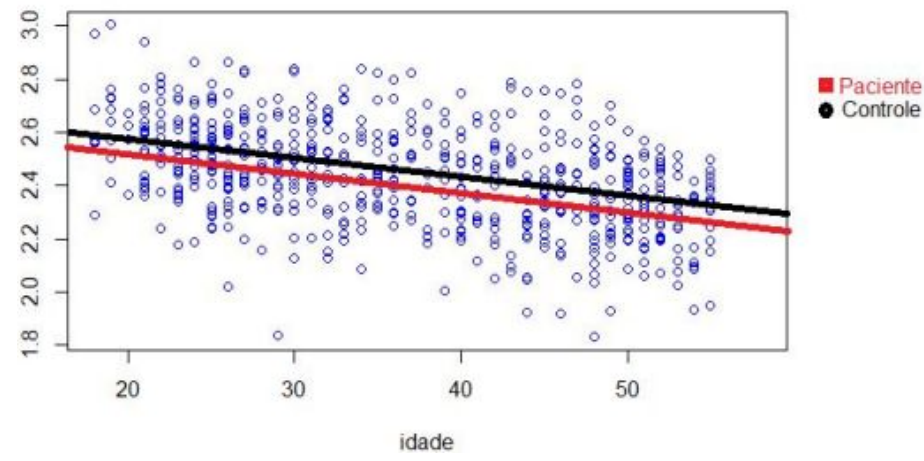

\section{Conclusões}

Pela análise de regressão feita, é possível concluir que existe diferença no envelhecimento do cérebro dos pacientes com epilepsia se comparado com pessoas saudáveis. $\mathrm{Na}$ maior parte dos casos, as regiões do cérebro analisadas dos pacientes encontram-se mais envelhecidas do que as regiões do cérebro de uma pessoa saudável com a mesma idade, porém, existem exceções. 